\title{
Influenza Vaccination During Pregnancy And Influencing Factors In Korea: A Multicenter Questionnaires Study of Pregnant Women and Obstetrics and Gynecology Doctors.
}

\section{Byung Soo Kang}

Seoul Saint Mary's Hospital https://orcid.org/0000-0003-2515-8536

\section{San Ha Lee}

Seoul Saint Mary's Hospital

Woo Jeng Kim

Seoul Saint Mary's Hospital

Jeong Ha Wie

Catholic University of Korea Eunpyeong St Mary's Hospital

In Yang Park

Seoul Saint Mary's Hospital

Hyun Sun Ko ( $\square$ mongkoko@catholic.ac.kr)

Seoul St. Mary's Hospital https://orcid.org/0000-0001-6310-6206

\section{Research article}

Keywords: influenza, maternal, vaccination

Posted Date: September 28th, 2020

DOI: https://doi.org/10.21203/rs.3.rs-76094/v1

License: (c) (i) This work is licensed under a Creative Commons Attribution 4.0 International License. Read Full License

Version of Record: A version of this preprint was published at BMC Pregnancy and Childbirth on July 16th, 2021. See the published version at https://doi.org/10.1186/s12884-021-03984-2. 


\section{Abstract}

\section{Background}

Our objective was to investigate: (1) the proportion of influenza vaccination, attitudes, and barriers among pregnant women, (2) the proportion of obstetrics and gynecology (OBGYN) doctors who routinely recommend influenza vaccination in pregnant women, and (3) the influencing factors in Korea, during the flu season of 2019-2020, following the introduction of free influenza vaccination program for pregnant women.

\section{Methods}

Two separate anonymized questionnaires were developed for pregnant or postpartum women and physicians, and distributed to public or private healthcare centers and clinics, in South Korea. The proportions of women who received influenza vaccination during pregnancy and OBGYN doctors who routinely recommend influenza vaccine for pregnant women were analyzed. Independent influencing factors of influenza vaccination and OBGYN doctors' routine recommendation for pregnant women were analyzed using multivariate logistic regression analysis, respectively.

\section{Result}

The self-reported proportion of influenza vaccination during pregnancy among 522 women was $63.2 \%$. Independent factors influencing maternal influenza vaccination were '(ever) received information about influenza vaccination during pregnancy', 'information obtained from OBGYN doctors', and '2nd/3rd trimester or postpartum period' (OR 8.988, 95\% Cl 4.21-19.188, $\mathrm{p}<0.001, \mathrm{OR} 2.611,95 \% \mathrm{Cl} 1.705-3.998$, $\mathrm{p}<0.001$ and $\mathrm{OR} 3.082,95 \% \mathrm{Cl} 1.508-6.297, \mathrm{p}<0.001$, respectively).

In 372 OBGYN doctors, the proportion of doctors with the routine recommendation of influenza vaccine for pregnant women was $76.9 \%$. Independent factors affecting the routine recommendation were: 1 ) affiliation with private hospital or clinic (OR 4.508, 95\% Cl 2.225-9.133, $p<0.001)$; 2 ) awareness of guidelines (OR 3.153, 95\% Cl 1.118-8.894, p=0.03); (3) awareness of 2019 National free influenza vaccination program for pregnant women (OR 4.955, 95\% Cl 2.377-10.329, $\mathrm{p}<0.001)$. For a future recommendation of influenza vaccine for pregnant women, the guidelines proposed by the government or public health care [108 (46\%)] and academic committees [59 (25\%)] were most commonly chosen by OBGYN doctors.

\section{Conclusion}

This study demonstrated that providing information about maternal influenza vaccination and the recommendation by OBGYN doctors are crucial for increasing the vaccination coverage in pregnant women.

\section{Background}


Pregnant women with altered immunity and increased cardiopulmonary burden during pregnancy are at high risk of influenza-related complications compared with the general population [1, 2]. In the 2009 H1N1 influenza pandemic season, the maternal infection was associated with severe complications resulting in maternal death and admission to an intensive care unit [3]. In addition, influenza vaccine is not licensed for use in infants under the age of 6 months. Therefore, infants aged below 6 months cannot be protected except through maternal immunization. According to the global statistics, approximately 228,000 (95\% Cl 150,000 to 344,000) hospitalizations in infants $<6$ months, were associated with influenza, annually [4]. According to the previous studies, infants less than 6 months of age, with confirmed influenza infection, were at the highest risk of hospitalization due to influenza, neurologic or pulmonary complications and admission to intensive care unit $[5,6]$. Several studies have demonstrated the effectiveness of maternal influenza vaccination for protection of infants aged below 6 months from influenza illness, respiratory infections, and severe pneumonia $[7,8]$.

Although, the World Health Organization (WHO) and health authorities in most countries recommend pregnant women to receive the inactivated influenza virus vaccine [9-12], the coverage is still limited. Since 2012, the Korean Centers for Disease Control and Prevention (KCDC) also has recommended vaccination of pregnant women and women contemplating pregnancy during the flu season under the 'Guidelines of Vaccination for Adults' [13]. However, it has been reported that vaccination rate associated with pregnancy was less than $40 \%[14,15]$. A National free immunization program about influenza was developed for pregnant women to increase vaccine coverage during the flu season of 2019-2020 in Korea. Our objectives were to 1) investigate the proportion of influenza vaccination in pregnant women and influencing factors, and 2) investigate the proportion of obstetrics and gynecology (OBGYN) doctors who routinely recommend influenza vaccine for pregnant women and influencing factors.

\section{Methods}

\section{Survey Questionnaires}

Two different questionnaires were developed and used anonymously to survey pregnant or postpartum women (within 6 weeks after birth) and OBGYN doctors (Suppl 1\&2). The questionnaires were adapted from the previously self-administered questionnaires [16-18], with a multidisciplinary study team including OBGYN doctors, biomedical statisticians and pregnant women. A pilot survey involving both target groups was performed to ensure comprehensiveness. Because some women or OBGYN doctors did not know that the 'National free influenza vaccination program' in 2019-2020 flu season include pregnant women yet, we added an answer 'free vaccination program' in the question $10-2$.

The questionnaire for pregnant or postpartum women assessed characteristics including age, pregnancy duration, parity, natural conception or use of assisted reproduction, education level, occupation, and administrative district of residential areas. The questionnaire for physicians asked about characteristics including age, sex, recent maternity care, and characteristics of working clinics/hospitals (private or public) and its located administrative district. Residential areas of pregnant or postpartum women and 
physicians' work locations were divided into metropolitan and non-metropolitan areas. Metropolitan areas included Seoul, Busan, Gwangju, Incheon, Ulsan, Daejeon, and Sejong and Kyunggi provinces around Seoul. Non-metropolitan areas included Chuncheon, Gyeongsang, Jeolla, Gangwon, and Jeju provinces.

Pregnant or postpartum women were asked (1) whether they received influenza vaccination during pregnancy in the 2019-2020 flu season; (2) whether or not they received information about influenza vaccination; (3) information sources; (4) influenza vaccination during previous pregnancy; (5) the reasons for not receiving influenza vaccine; and (6) the factors influencing future vaccination. The women were classified depending on whether or not they reported being vaccinated during the flu season of 20192020. The question regarding information sources allowed for multiple responses. If a response included OBGYN doctors with or without other sources, it was designated to 'OBGYN doctors'. If a response included other sources of public health care, media, friends, or family, but not included 'OBGYN doctors', it was designated to 'other sources'.

OBGYN doctors were grouped according to routine recommendations of influenza vaccines for pregnant women based on an affirmative response to the question, "Do you recommend influenza vaccines to pregnant women in your clinic?" OBGYN doctors who answered, 'always recommend vaccination' were designated as the 'routine recommendation group' and OBGYN doctors who responded 'sometimes or never recommended vaccination' were designated as the 'passive recommendation group'. Physicians' awareness of '2019 National free influenza vaccination program for pregnant women' and government recommendations, such as 'all pregnant or breastfeeding women during flu season are primarily recommended to receive an inactive influenza vaccine, were evaluated. Their attitudes were analyzed based on their response to the following questions: 1) Do you provide information about influenza vaccine to pregnant women? 2) Do you recommend influenza vaccine during pregnancy?

Also, the survey sought to determine physician's own influenza vaccination during the previous flu season. Physicians were asked about 'influencing factors' for a future recommendation of influenza vaccination in pregnant women. Ethical approval was granted by the institutional review board of the Catholic University of Korea (KC19QES10646).

\section{Study Population And Recruitment}

The survey was conducted from October 15, 2019 to December 31, 2019. The questionnaires were distributed to medical doctors who are registered in Korean society of Maternal-fetal medicine (KSMFM), Korean society of perinatal medicine (KSPM), Korean association of obstetrics and gynecology (KAOG), or Korean society of ultrasound in obstetrics and gynecology (KSUOG). The paper questionnaires or an online link to the survey using Google forms for women participants were distributed in person via opportunistic sampling at antenatal clinics or wards, by medical doctors or trained assistants. 
The physician questionnaire was distributed to medical doctors who were registered in KSMFM, KSPM, KAOG, or KSUOG, via paper or an online link to the survey using Google forms, by e-mail. The participation was voluntary, and no financial or other incentives were offered. The response to this survey implied their consent. Information provided by the participants was voluntary and possibly incomplete.

The sample size for a survey of pregnant or postpartum women was calculated with the following assumptions: $50 \%$ of women in pregnancy took influenza vaccination, a confidence interval of $95 \%$, and alpha of 0.05 . The initial calculated minimum sample size was 384 participants, but considering the nonresponse rate $(10 \%)$ and the incomplete rate $(30 \%)$ to the questionnaire, 538 pregnant women were required to meet the minimum sample size. The sample size for a survey of OBGYN doctors was calculated based on the estimation that $60 \%$ of the OBGYN doctors routinely recommend influenza vaccination for pregnant women, a $95 \%$ confidence interval, and alpha of 0.05 . Therefore, the estimated minimum number of OBGYN doctors required was estimated at 360 . In addition, accounting for the response rate of $55 \%$, the minimum number of participants required was estimated as 640 .

\section{Data analysis}

Data analysis was performed using SPSS (version 24.0, Chicago, IL, USA). Categorical data were expressed as number (\%) and compared using Chi-square test. Continuous variables were presented as mean \pm standard deviation and compared using Student's t-test. To assess independent predictors of vaccine uptake by pregnant women, we calculated the odds ratios (ORs) and $95 \%$ confidence intervals (Cls) using logistic regression models, adjusted for maternal age and metropolitan residence which were variables with statistical cutoff, $P<0.07$, between vaccinated and unvaccinated groups, in univariate analysis.

Multivariate logistic regression analysis for independent predictors associated with OBGYN doctors' routine recommendation of influenza vaccination was adjusted for physician's age, sex, and location of clinic/hospital. Statistical significance was set at $P<0.05$.

\section{Result}

\section{Demographic characteristics of pregnant women}

A total of 522 questionnaires were eligible to be analyzed, after excluding 34 incomplete questionnaires, which had not responded whether they had vaccinated or not. Questionnaires were collected via an online survey $(10.2 \%, 53 / 522)$, and paper survey $(89.8 \%, 487 / 522)$. Residential distribution of pregnant/postpartum women is presented in Fig. 1(A) and suppl 3, which indicates that $80.8 \%$ of respondents lived in the metropolitan area.

Demographic characteristics associated with influenza vaccination are presented in Table 1. There were significant differences in the gestational period and metropolitan residence, between two groups. Women in the vaccinated group were significantly more informed about the influenza vaccine compared with 
women in the unvaccinated group $(p<0.001)$. Besides, women in the vaccinated group were more informed by OBGYN doctors than women in the unvaccinated group $(p<0.001)$.

Table 1

Demographic characteristics of pregnant or postpartum women associated with influenza vaccination during pregnancy.

\begin{tabular}{|c|c|c|c|}
\hline Characteristics & $\begin{array}{l}\text { Vaccinated(n } \\
=330)\end{array}$ & $\begin{array}{l}\text { Unvaccinated(n } \\
=192)\end{array}$ & $\begin{array}{l}\mathrm{p}- \\
\text { value }\end{array}$ \\
\hline Maternal age $(y r)($ mean \pm SD) & $33.32 \pm 3.85$ & $33.18 \pm 4.53$ & 0.069 \\
\hline Gestational age (weeks) (mean \pm SD) & $31.28 \pm 20.27$ & $26.31 \pm 9.12$ & 0.002 \\
\hline Pregnancy period & & & 0.002 \\
\hline$\leq 13$ weeks $(n, \%)$ & $17(5.2)$ & $25(13.0)$ & \\
\hline 14-27 weeks(n, \%) & $67(20.3)$ & $45(23.4)$ & \\
\hline$\geq 28$ weeks $\sim(n, \%)$ & $230(69.7)$ & 108(56.3) & \\
\hline Postpartum(n, \%) & $16(4.8)$ & $14(7.3)$ & \\
\hline Nulliparous women $(\mathrm{n}, \%)$ & $219(66.4)$ & $122(63.5)$ & 0.514 \\
\hline Assisted reproduction (n, \%) & $29(6.6)$ & $19(9.9)$ & 0.79 \\
\hline Education (college degree or higher) (n, \%) & $304(92.1)$ & $168(87.5)$ & 0.084 \\
\hline Metropolitan residence(n, \%) & $270(81.8)$ & $15(79.2)$ & 0.047 \\
\hline Occupation & & & 0.186 \\
\hline housewife(n, \%) & $145(43.9)$ & $73(38.0)$ & \\
\hline other than housewife(n, \%) & $185(56.1)$ & $119(62.0)$ & \\
\hline $\begin{array}{l}\text { (Ever) received information about influenza vaccination } \\
\text { during pregnancy }(\mathrm{n}, \%)\end{array}$ & $321(97.3)$ & $155(80.7)$ & $<.001$ \\
\hline Source of information & & & $<.001$ \\
\hline OBGYNª doctors(n, \%) & $239(72.4)$ & $83(43.2)$ & \\
\hline $\begin{array}{l}\text { Non-OBGYN doctors, public health care, media, friends } \\
\text { or family }(n, \%)\end{array}$ & $91(27.6)$ & $109(56.8)$ & \\
\hline Influenza vaccination in the previous pregnancy $(n, \%)^{b}$ & $71(61.6)$ & $34(32.4)$ & 0.096 \\
\hline
\end{tabular}

Values are presented as mean \pm standard deviation or $\mathrm{n}(\%)$. 
Influencing factors for maternal influenza vaccination using univariate and multivariate analysis

In univariate analysis, '(ever) received information about influenza vaccination during pregnancy', 'received information from OBGYN doctors', and 'second/third trimester' were significantly associated with maternal influenza vaccination. In multivariate analysis adjusted for maternal age and metropolitan residential status, '(ever) received information about influenza vaccination during pregnancy' significantly increased odds for vaccination (OR 8.988, 95\% Cl 4.21-19.188, $\mathrm{p}<0.001)$. 'received information from OBGYN doctors', and 'second/third trimester' were also independent factors influencing influenza vaccination (OR 2.611, 95\% Cl 1.705-3.998, p < 0.001 and OR 3.082, 95\% Cl 1.508-6.297, p<0.001, respectively). (Table 2 )

Table 2

Influencing factors for maternal influenza vaccination using univariate and multivariate analysis

\begin{tabular}{|c|c|c|c|c|c|c|}
\hline & \multicolumn{3}{|c|}{$\begin{array}{l}\text { Univariate } \\
\text { analysis }\end{array}$} & \multicolumn{3}{|c|}{$\begin{array}{l}\text { Multivariate } \\
\text { analysis }\end{array}$} \\
\hline & OR & $95 \% \mathrm{Cl}$ & $\begin{array}{l}\mathrm{p}- \\
\text { value }\end{array}$ & $\begin{array}{l}\text { Adjusted } \\
\mathrm{OR}^{\mathrm{a}}\end{array}$ & $95 \% \mathrm{Cl}$ & $\begin{array}{l}\mathrm{p}- \\
\text { value }\end{array}$ \\
\hline \multicolumn{7}{|l|}{$\begin{array}{l}\text { (ever) received information about } \\
\text { influenza vaccination }\end{array}$} \\
\hline No & 1 & & & 1 & & \\
\hline Yes & 8.514 & $\begin{array}{l}4.009- \\
18.083\end{array}$ & $\begin{array}{l}< \\
0.001\end{array}$ & 8.988 & $4.21-19.188$ & $\begin{array}{l}<.001 \\
0.001\end{array}$ \\
\hline \multicolumn{7}{|l|}{ Source of information } \\
\hline $\begin{array}{l}\text { Non-OBGYNa doctors, public } \\
\text { health care, media, friends and } \\
\text { family }\end{array}$ & 1 & & & 1 & & \\
\hline OBGYN ${ }^{b}$ doctors & 2.62 & $\begin{array}{l}1.729- \\
3.971\end{array}$ & $<.001$ & 2.611 & $\begin{array}{l}1.705- \\
3.998\end{array}$ & $\dot{0} 001$ \\
\hline \multicolumn{7}{|l|}{ Pregnancy period } \\
\hline 1 st trimester & 1 & & & 1 & & \\
\hline 2nd and 3rd trimester, & 2.756 & $\begin{array}{l}1.447- \\
5.249\end{array}$ & 0.001 & 3.082 & $\begin{array}{l}1.508- \\
6.297\end{array}$ & 0.001 \\
\hline \multicolumn{7}{|c|}{ aAdjusted for maternal age and metropolitan residence } \\
\hline bOBGYN, Obstetrics and gynae & & & & & & \\
\hline
\end{tabular}

\section{Barriers Against Influenza Vaccination And Factors For Future Vaccination}


Among 192 women in the unvaccinated group, 169 women (88\%) responded to the question about the reasons for not receiving influenza vaccine. 59 (34.9\%) women replied, 'I didn't know that I should be vaccinated' and 37 (21.9\%) women answered, 'I'm planning to have vaccination at the time of vaccination schedule, but waiting for the appropriate time'. 73 (43.2\%) women replied, 'I didn't want to have an influenza vaccination'. About 'the reasons for not wanting influenza vaccination', all respondents $(n=73)$ answered 'not knowing the importance of vaccine' (Table 3).

Among 192 women included in the unvaccinated group, 92 women responded to the question about influencing factors for future vaccination, allowing multiple responses, "If you didn't know the importance of vaccination, in which case would you get the vaccination?". 122 choices were received from 92 women. A majority of the respondents $(n=81,88 \%)$ said that they will receive the influenza vaccine in the future if obstetricians recommend influenza vaccination.

Table 3

Reasons for not wanting influenza vaccination in unvaccinated women and factors for future vaccination during pregnancy

\section{Reasons for not wanting influenza vaccination in unvaccinated women (multiple responses)(Total responders, $n=73$ ).}

Not knowing the importance of vaccine $48(66 \%)$

Not knowing the importance of vaccine + Distrust of effect

$1(1 \%)$

Not knowing the importance of vaccine + Fear of side effect

$1(1 \%)$

Not knowing the importance of vaccine + others

$23(32 \%)$

Major influencing factors for future vaccination during pregnancy (multiple responses) (Total responders, $\mathrm{n}=92$ ).

OBGYN doctors ${ }^{\mathrm{a}}$

Other medical doctors ${ }^{b}$

Family or friends

$4(2.1 \%)$

TV/Radio/Paper/Internet

Free vaccination program $16(17.4 \%)$

Pediatric doctors

${ }^{b} O B G Y N$, Obstetrics and gynaecology, ${ }^{b}$ Other medical doctors: medical doctors except OBGYN or pediatric doctors

\section{Demographic Characteristics, Awareness, And Attitudes Of Obgyn Doctors}


A total of 373 questionnaires were eligible to be analyzed, after excluding 3 incomplete responses and 86 responses from non-OBGYN doctors. Questionnaires were collected via an on-line survey $(88.7 \%$, $331 / 373)$, and paper survey (11.3\%, 42/373). As shown in Fig. 1(B) and suppl 3, the distribution of OBGYN doctors' clinics/hospitals suggests that $80.5 \%$ of respondents worked in metropolitan areas, with $37.8 \%$ in Seoul and $43.2 \%$ in Gyeonggi and other metropolitan cities. Demographic characteristics, awareness and attitudes are presented in Table 4. 287 (76.9\%) of the 373 OBGYN doctors included in the routine recommendation group. Significant differences were found between routine and passive recommendation groups in 1) affiliation with private clinic/hospital; 2) personal influenza vaccination in the previous year; 3 ) provided maternity care within the last 5 years; 4 ) awareness of KCDC guidelines; 5 ) consensus on the recommendation of influenza vaccine during pregnancy; 6 ) appropriate time for influenza vaccination during pregnancy; 7) awareness of 2019 National free influenza vaccination program for pregnant women. 
Table 4

Demographic characteristics, awareness, and attitudes of OBGYN doctors, associated with recommendation of Maternal influenza vaccination.

\begin{tabular}{|c|c|c|c|}
\hline Characteristics & $\begin{array}{l}\text { Routine } \\
\text { recommendation } \\
\text { group }(n=287)\end{array}$ & $\begin{array}{l}\text { Passive } \\
\text { recommendation } \\
\text { group }(n=86)\end{array}$ & $\begin{array}{l}\mathrm{p} \\
\text { value }\end{array}$ \\
\hline Age (years old) (mean \pm SD) & $47.51 \pm 9.4$ & $45.76 \pm 12.52$ & 0.231 \\
\hline Female (n, \%) & $154(53.7)$ & $54(62.8)$ & 0.135 \\
\hline Private clinic/hospital (n, \%) & 263(91.6) & $54(62.8)$ & $<.001$ \\
\hline Metropolitans area $(n, \%)$ & $231(80.5)$ & $71(82.6)$ & 0.668 \\
\hline $\begin{array}{l}\text { Provided maternity care within the last } 5 \text { years }(\mathrm{n} \text {, } \\
\%)\end{array}$ & 259(90.2) & $68(79.1)$ & 0.006 \\
\hline $\begin{array}{l}\text { Received influenza vaccination in the previous year } \\
(\mathrm{n}, \%)\end{array}$ & $272(94.8)$ & $71(82.6)$ & $<.001$ \\
\hline $\begin{array}{l}\text { Awareness of safety, importance and priority } \\
\text { groups of vaccination before, during and after } \\
\text { delivery, recommended by } \operatorname{KCDC} C^{a} \text { guidelines }(n, \%)\end{array}$ & 278(96.9) & $68(79.1)$ & $<.001$ \\
\hline $\begin{array}{l}\text { Do you provide information about influenza } \\
\text { vaccine to pregnant women? }\end{array}$ & & & $<.001$ \\
\hline Always (n, \%) & $276(96.2)$ & $8(9.3)$ & \\
\hline Sometimes (n, \%) & $11(3.8)$ & $61(70.9)$ & \\
\hline No $(n, \%)$ & $0(0)$ & $17(19.8)$ & \\
\hline \multirow{2}{*}{$\begin{array}{l}\text { Appropriate time for influenza vaccination related } \\
\text { to pregnancy }{ }^{b}(n, \%)\end{array}$} & $158(70.2 \%)$ & $33(49.3 \%)$ & \multirow[t]{5}{*}{0.001} \\
\hline & $61(27.1 \%)$ & $26(38.8 \%)$ & \\
\hline All trimesters, prepregnancy, and postpartum & $6(2.7 \%)$ & 8 (11.9\%) & \\
\hline $\begin{array}{l}\text { 2nd and 3rd trimester, prepregnancy, and } \\
\text { postpartum }\end{array}$ & & & \\
\hline 2nd and 3rd trimester, and postpartum & & & \\
\hline $\begin{array}{l}\text { Awareness about } 2019 \text { pregnant women free } \\
\text { vaccination }(n, \%)\end{array}$ & $268(93.4)$ & $51(59.3)$ & $<.001$ \\
\hline
\end{tabular}

Univariate and multivariate analyses of factors for OBGYN doctors' recommendation of influenza vaccination

In both univariate and multivariate analyses, 1 ) working at private clinic/hospital (OR $4.508,95 \% \mathrm{Cl}$ $2.225-9.133, p<0.001), 2$ ) awareness of guidelines (OR 3.153, 95\% $\mathrm{Cl} 1.118-8.894, \mathrm{P}=0.03$ ), and (3) 
awareness of 2019 National free influenza vaccination program for pregnant women (OR 4.955, 95\% Cl 2.377-10.329, $p<0.001$ ) were significantly independent factors for 'routine recommendation' (Table 5).

Table 5

Univariate and Multivariate logistic regression analyses.

\begin{tabular}{|c|c|c|c|c|c|c|}
\hline & \multicolumn{3}{|c|}{ Univariate analysis } & \multicolumn{3}{|c|}{ Multivariate analysis } \\
\hline & OR & $95 \% \mathrm{Cl}$ & $\begin{array}{l}\mathrm{p}- \\
\text { value }\end{array}$ & OR & $95 \% \mathrm{Cl}$ & $\begin{array}{l}\text { p- } \\
\text { value }\end{array}$ \\
\hline Working at private clinic or hospital & 6.494 & $\begin{array}{l}3.547- \\
11.89\end{array}$ & $<.001$ & 4.508 & $\begin{array}{l}2.225- \\
9.133\end{array}$ & $<.001$ \\
\hline $\begin{array}{l}\text { Provided maternity care within the last } \\
5 \text { years }\end{array}$ & 2.449 & $\begin{array}{l}1.279- \\
4.688\end{array}$ & 0.006 & 1.865 & $\begin{array}{l}0.862- \\
4.033\end{array}$ & 0.113 \\
\hline $\begin{array}{l}\text { Received influenza vaccination in the } \\
\text { previous year }\end{array}$ & 3.831 & $\begin{array}{l}1.788- \\
8.207\end{array}$ & $<.001$ & 2.571 & $\begin{array}{l}0.96- \\
6.882\end{array}$ & 0.06 \\
\hline $\begin{array}{l}\text { Awareness of safety, importance and } \\
\text { priority groups of vaccination before, during } \\
\text { and after delivery, recommended by } \mathrm{KCDC}^{\mathrm{a}} \\
\text { guidelines }\end{array}$ & 8.176 & $\begin{array}{l}3.519- \\
18.996\end{array}$ & $<001$ & 3.153 & $\begin{array}{l}1.118- \\
8.894\end{array}$ & 0.03 \\
\hline $\begin{array}{l}\text { Awareness about } 2019 \text { pregnant women } \\
\text { free vaccination }\end{array}$ & 9.68 & $\begin{array}{l}5.136- \\
18.243\end{array}$ & $<.001$ & 4.955 & $\begin{array}{l}2.377- \\
10.329\end{array}$ & $<.001$ \\
\hline \multicolumn{7}{|c|}{ Multivariate logistic regression analysis was adjusted for age, sex, location of clinic (hospital) } \\
\hline
\end{tabular}

Factors expected to affect for a future recommendation for maternal influenza vaccination (multiple responses)

Among 235 choices from 217 respondents, the guidelines recommended by government or public healthcare [108 (46\%)] and academic committees [59 (25\%)] were suggested as major factors influencing OBGYN doctors' future recommendation for maternal influenza vaccination. Other factors included academic papers and lectures [31 (13\%)], media advertisements [28(12\%)], and free vaccination [9(4\%)].

\section{Discussion}

In this study, $63.2 \%$ of responded pregnant women had an influenza vaccination and, $76.9 \%$ of responded OBGYN doctors routinely recommended influenza vaccine for pregnant women, Both univariate and multivariate analyses showed that '(ever) received information about influenza vaccination during pregnancy' was the most significant factor to get an influencing influenza vaccination in pregnant women. Also, 'received information from OBGYN doctors', and 'second/third trimester' were independent influencing factors for influenza vaccination. The most significant barrier about influenza vaccination 
was the lack of awareness in pregnant women. In the survey for OBGYN doctors working in private rather than public clinics/hospitals, the awareness of KCDC guidelines for influenza vaccination for pregnant women and the 'National Free Influenza Vaccination Program for Pregnant Women in 2019 Flu Season' were independent factors for routine recommendation of OBGYN doctors.

The pregnancy-related vaccination rates in USA were between $49.1 \%$ and 53.6\% from 2015 to 2018 [19]. In Europe, the highest vaccination rates reported in pregnant women were $62 \%$ and $58 \%$ during $2017-18$ and 2016-2017 flu seasons, respectively, in Ireland [20]. The highest vaccination rate during pregnancy in Western Australia was 61\% in 2015 [21]. Previous questionnaire studies from Korea reported 35-40\% vaccination rates in pregnant women $[14,15]$. However, the vaccination coverage in the overall pregnant population of Korea has been unknown until 2018-2019 flu season, because influenza vaccination was not covered by insurance and performed in a private area. We speculate that the National free influenza vaccination program started in 2019-2020 flu season of Korea might increase the awareness of vaccination and confidence among OBGYN doctors, which may result in an increased routine recommendation for pregnant women. A past study from Korean obstetricians about maternal influenza vaccination reported that only $26.5 \%$ of obstetricians strongly recommended maternal influenza vaccination [22]. It is well known that advice and encouragement from familiar healthcare professionals (HCPs) significantly improve vaccine acceptance by pregnant women [23]. Also, several studies have shown that HCPs' knowledge about vaccine efficacy and safety is considerably associated with their vaccine recommendation. HCPs' confidence about vaccination is crucial for vaccination implementation in pregnant women [24-26]. Because OBGYN doctors are most familiar with pregnant women's conditions, the professional information and recommendations provided by them may directly affect vaccination decisions. Because most of the OBGYN doctors considered 'guidelines for vaccination' as an important factor for a future recommendation, further education of existing guidelines and supporting 'position statements' or 'programs' by the academic committee, especially related to maternal-fetal medicine, might increase the routine recommendation by OBGYN doctors, by increasing their confidence.

This study has several limitations. First, this study included all provinces of Korea to maximize the demographic diversity of study populations. However, it cannot be considered as representative of all pregnant women and OBGYN doctors in Korea. Secondly, although we distributed the survey by academic committees, the responded doctors and hospitals may have a positive attitude toward vaccination, which can increase the possibility of selection bias. Thirdly, the self-reported vaccination status may lead to potential reporting bias in our estimation. Lastly, the number of non-respondents among the surveyed pregnant women/OBGYN doctors was not recorded.

This study also has several strengths. First, this study had significant numbers of respondents who lived or worked not only in metropolitan areas but also in non-metropolitan areas. Although only about $20 \%$ of respondents lived in local provinces, it correlated with the percentage of live births in local provinces, which was about $30 \%$ of all births in Korea [27]. In pregnant women, there was no significant difference in terms of residential area distribution between vaccinated and unvaccinated groups. Also, the effect of physicians' workplace location between routine and passive recommendation groups was insignificant. 
The surveys of pregnant women and OBGYN doctors were conducted anonymously, thereby allowing free expression of opinions by the responders. Most importantly, over doubled proportion of OBGYN doctors who routinely recommend maternal influenza vaccination, compared to previous similar studies, were correlated with significantly increased proportion of maternal influenza vaccination, in this study.

\section{Conclusion}

In this study, the proportion of pregnant women who reported receiving influenza vaccination was $63.2 \%$, and the proportion of OBGYN doctors who routinely recommend it was $76.9 \%$, respectively. Based on the high acceptance rates of preventive vaccines in Korea [28,29], maternal influenza vaccination can be more successful in the future, if the information is provided appropriately. Close cooperation between $\mathrm{KCDC}$ and academic societies including obstetrics and gynecology is crucial for the confidence of OBGYN doctors and their routine recommendations, in order to enhance influenza vaccination during pregnancy, which can maximize the benefits of the vaccine for both mothers and infants.

\section{Abbreviations}

OBGYN, Obstetrics and gynecology

WHO, World Health Organization

KCDC, Korean Centers for Disease Control and Prevention

KSMFM, Korean society of Maternal-fetal medicine

KSPM, Korean society of perinatal medicine (KSPM)

KAOG, Korean association of obstetrics and gynecology (KAOG)

KSUOG, Korean society of ultrasound in obstetrics and gynecology (KSUOG)

\section{Declarations}

\section{Ethics approval and consent to participate}

Ethical approval was granted by the institutional review board of the Catholic University of Korea (KC19QES10646). The voluntary response to this survey implied their consent and written consents were exampted. This study is in compliance with the 2013 Helsinki World Medical Association.

\section{Consent for publication}

This work has not been published before nor is it under consideration for publication elsewhere. The contents of this manuscript will not be copyrighted, or published elsewhere while acceptance by your 
journal is under consideration.

\section{Availability of data and material}

All relevant data are within the paper and its Supporting Information files.

\section{Competing interests}

The authors declare that they have no competing interests

\section{Funding}

This research was supported by a fund by Research of Korea Centers for Disease Control and Prevention and the Catholic Medical Center Research Foundation made in the program year of 2019.

\section{Author Contributions}

HSK conceptualized, investigated, analyzed, supervised, and edited the study. BKS analyzed the study and wrote the original draft. SHL, WJK and JHW investigated and administrated the study. IYP edited the study. All authors read and approved the final manuscript.

\section{Acknowledgments}

The authors wish to acknowledge cooperation of Korean society of Maternal-fetal medicine, Korean society of perinatal medicine, Korean association of obstetrics and gynecology, and Korean society of ultrasound in obstetrics and gynecology. The authors would like to thank all participating women and healthcare professionals. We also thank the staffs of Seoul St. Mary's hospital (Mikyung Park and Yuri Jang) for their assistance in carrying out this survey.

\section{References}

1. Neuzil KM, Reed GW, Mitchel EF, Simonsen L, Griffin MR. Impact of influenza on acute cardiopulmonary hospitalizations in pregnant women. Am J Epidemiol. 1998; 148:1094-1102. https://doi.org/10.1093/oxfordjournals.aje.a009587 PMID: 9850132

2. Centers for Disease Control and Prevention (CDC). Maternal and infant outcomes among severely ill pregnant and postpartum women with 2009 pandemic influenza A (H1N1)-United States, April 2009August 2010. MMWR Morb Mortal Wkly Rep. 2011; 60:1193-1196. PMID: 21900872

3. Choi WS, Choi MJ, Noh JY, Song JY, Kim WJ, Park DW, et al. Clinical and economic analysis of the 2009 H1N1 influenza pandemic among pregnant Korean women. Korean J Intern Med. 2019; 34:1136-1144. https://doi.org/10.3904/kjim.2017.107 PMID: 29232939

4. Lafond KE, Nair H, Rasooly MH, Valente F, Booy R, Rahman M, et al. Global Role and Burden of Influenza in Pediatric Respiratory Hospitalizations, 1982-2012: A Systematic Analysis. PLoS Med. 2016; 13:e1001977. https://doi.org/10.1371/journal.pmed.1001977 PMID: 27011229 
5. Kim S, Moon HM, Lee JK, Rhie K, Yoon KW, Choi EH, et al. Changes in trends and impact of testing for influenza in infants with fever $<90$ days of age. Pediatr Int. 2017; 59:1240-1245. https://doi.org/10.1111/ped.13428 PMID: 28940983

6. Chong CY, Yung CF, Gan C, Thio ST, Tan NW, Tee NW, et al. The burden and clinical manifestation of hospitalized influenza among different pediatric age-groups in the tropics. Influenza Other Respir Viruses. 2020; 14:46-54. https://doi.org/10.1111/irv.12692 PMID: 31608598

7. Zaman K, Roy E, Arifeen SE, Rahman M, Raqib R, Wilson E, et al. Effectiveness of maternal influenza immunization in mothers and infants. N Engl J Med. 2008; 359:1555-1564. https://doi.org/10.1056/NEJMoa0708630 PMID: 18799552

8. Omer SB, Clark DR, Aqil AR, Tapia MD, Nunes MC, Kozuki N, et al. Maternal Influenza Immunization and Prevention of Severe Clinical Pneumonia in Young Infants: Analysis of Randomized Controlled Trials Conducted in Nepal, Mali and South Africa. Pediatr Infect Dis J. 2018; 37:436-440. https://doi.org/10.1097/INF.0000000000001914 PMID: 29443825

9. Centers for Disease Control and Prevention (CDC). Prevention and control of seasonal influenza with vaccines. Recommendations of the Advisory Committee on Immunization Practices--United States, 2013-2014. MMWR Recomm Rep. 2013; 62:1-43. PMID: 24048214

10. World Health Organization. Vaccines against influenza WHO position paper - November 2012. Wkly Epidemiol Rec. 2012; 87:461-476. PMID: 23210147

11. World Health Organization. Meeting of the Strategic Advisory Group of Experts on immunization, April 2012-conclusions and recommendations. Wkly Epidemiol Rec. 2012; 87:201-216. PMID: 24340402

12. World Health Organization. H5N1 avian influenza: first steps towards development of a human vaccine. Wkly Epidemiol Rec. 2005; 80:277-278. PMID: 16171030

13. Korea Centers for Disease Control and Prevention. Guidelines of vaccination for adult. Chungbuk: Korea Centers for Disease Control and Prevention; 2019.

14. Jung EJ, Noh JY, Choi WS, Seo YB, Lee J, Song JY, et al. Perceptions of influenza vaccination during pregnancy in Korean women of childbearing age. Hum Vaccin Immunother. 2016; 12:1997-2002. https://doi.org/10.1080/21645515.2015.1119347 PMID: 27222241

15. Ko HS, Jo YS, Kim YH, Park YG, Moon HB, Lee Y, et al. Knowledge, attitudes, and acceptability about influenza vaccination in Korean women of childbearing age. Obstet Gynecol Sci. 2015; 58:81-89. https://doi.org/10.5468/ogs.2015.58.2.81 PMID: 25798420

16. Wilcox CR, Calvert A, Metz J, Kilich E, MacLeod R, Beadon K, et al. Determinants of Influenza and Pertussis Vaccination Uptake in Pregnancy: A Multicenter Questionnaire Study of Pregnant Women and Healthcare Professionals. Pediatr Infect Dis J. 2019; 38:625-630. https://doi.org/10.1097/INF.0000000000002242 PMID: 30418358

17. Maertens K, Braeckman T, Top G, Van Damme P, Leuridan E. Maternal pertussis and influenza immunization coverage and attitude of healthcareworkers towards these recommendations in 
Flanders, Belgium. Vaccine. 2016; 34:5785-5791. https://doi.org/10.1016/j.vaccine.2016.09.055 PMID: 27742214

18. Praphasiri P, Ditsungneon D, Greenbaum A, Dawood FS, Yoocharoen P, Stone DM, et al. Do Thai Physicians Recommend Seasonal Influenza Vaccines to Pregnant Women? A Cross-Sectional Survey of Physicians' Perspectives and Practices in Thailand. PLoS One. 2017; 12:e0169221. https://doi.org/10.1371/journal.pone.0169221 PMID: 28099486

19. Kahn KE, Black CL, Ding H, Williams WW, Lu PJ, Fiebelkorn AP, et al. Influenza and Tdap Vaccination Coverage Among Pregnant Women - United States, April 2018. MMWR Morb Mortal Wkly Rep. 2018; 67:1055-1059. https://doi.org/10.15585/mmwr.mm6738a3 PMID: 30260946

20. European Centre for Disease Prevention and Control. Seasonal influenza vaccination and antiviral use in EU/EEA Member States - Overview of vaccine recommendations for 2017-2018 and vaccination coverage rates for 2015-2016 and 2016-2017 influenza seasons. Stockholm: ECDC; 2018.

21. Mak DB, Regan AK, Vo DT, Effler PV. Antenatal influenza and pertussis vaccination in Western Australia: a cross-sectional survey of vaccine uptake and influencing factors. BMC Pregnancy Childbirth. 2018; 18:416. https://doi.org/10.1186/s12884-018-2051-3 PMID: 30355329

22. Noh JY, Seo YB, Song JY, et al. Perception and Attitudes of Korean Obstetricians about Maternal Influenza Vaccination. J Korean Med Sci. 2016;31(7):1063-1068. doi:10.3346/jkms.2016.31.7.1063

23. Wiley KE, Massey PD, Cooper SC, Wood NJ, Ho J, Quinn HE, et al. Uptake of influenza vaccine by pregnant women: a cross-sectional survey. Med J Aust. 2013; 198:373-375. https://doi.org/10.5694/mja12.11849 PMID: 23581957

24. Paterson P, Meurice F, Stanberry LR, Glismann S, Rosenthal SL, Larson HJ. Vaccine hesitancy and healthcare providers. Vaccine. 2016;34(52):6700-6706. doi:10.1016/j.vaccine.2016.10.042

25. Napolitano F, Navaro M, Vezzosi L, Santagati G, Angelillo IF. Primary care pediatricians' attitudes and practice towards HPV vaccination: A nationwide survey in Italy. PLoS One. 2018;13(3):e0194920. Published 2018 Mar 29. doi:10.1371/journal.pone.0194920

26. Leung SOA, Akinwunmi B, Elias KM, Feldman S. Educating healthcare providers to increase Human Papillomavirus (HPV) vaccination rates: A Qualitative Systematic Review. Vaccine X. 2019;3:100037. Published 2019 Aug 5. doi:10.1016/j.jvacx.2019.100037

27. Korean statistical information service. Statistics on birth rate by region. Daejeon: Korean statistical information service; http://kosis.kr/ Accessed April 10, 2020.

28. Yeo Y, Gwack J, Kang S, Koo B, Jung SJ, Dhamala P, et al. Viral hepatitis and liver cancer in Korea: an epidemiological perspective. Asian Pac J Cancer Prev. 2013; 14:6227-6231. https://doi.org/10.7314/apjcp.2013.14.11.6227 PMID: 24377509

29. Choe YJ, Yang JJ, Park SK, Choi EH, Lee HJ. Comparative estimation of coverage between national immunization program vaccines and non-NIP vaccines in Korea. J Korean Med Sci. 2013; 28:12831288. https://doi.org/10.3346/jkms.2013.28.9.1283 PMID: 24015031 


\section{Figures}

(A)

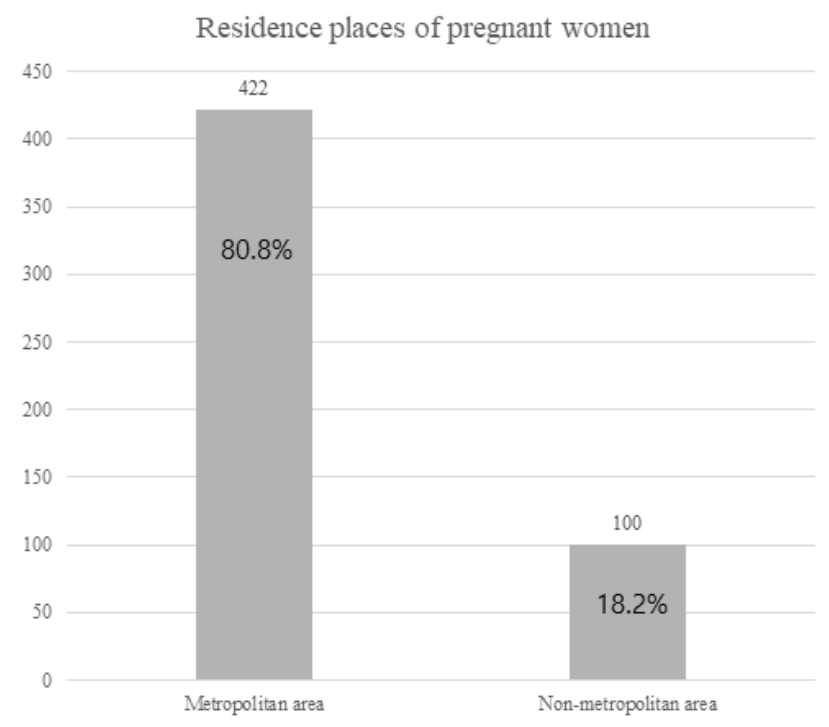

(B)

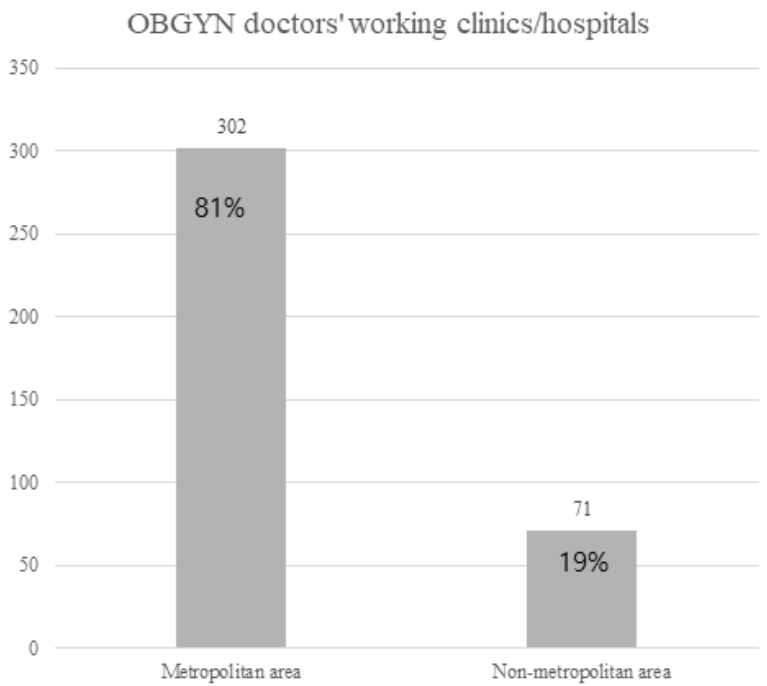

\section{Figure 1}

Geographical distributions of pregnant women and OBGYN doctors (A) Residences of pregnant women $(n=522)(B)$ OBGYN doctorsa working clinics/hospitals $(n=373)$ aOBGYN: obstetrics and gynecology

\section{Supplementary Files}

This is a list of supplementary files associated with this preprint. Click to download.

- Sup3map.docx

- sup2.docx

- sup1.docx 